\title{
CONDUTIVIDADE HIDRÁULICA DE AMOSTRAS REMOLDADAS DE UM LATOSSOLO ROXO DISTRÓFICO TRATADO COM ÁGUANINHAÇA ${ }^{(1)}$
}

\author{
E. J . V. LOBATO(2), P. L. LIBARDI ${ }^{(3)} \&$ O. A. CAMARGO(4)
}

\begin{abstract}
RESUMO
Este trabalho foi realizado no CENA/USP, Piracicaba, SP, com a finalidade de obter informações relativas aos efeitos da aplicação de água/vinhaça (nas dosagens de 100, 200, 400, 800 e $1.000 \mathrm{~m}^{3} \mathrm{ha}^{-1}$ ) na condutividade hidráulica de amostras remoldadas de um Latossolo Roxo distrófico, sob condições saturadas e não saturadas. E mpregou-se, para tanto, um infiltrômetro de carga constante, para a avaliação da condutividade hidráulica em solo saturado e, na caracterização da condutividade hidráulica em solo não saturado, utilizou-se o método do perfil instantâneo, sendo os dois experimentos realizados sob condições de laboratório. Com o aumento das dosagens de vinhaça, ocorreu um decréscimo gradativo da condutividade hidráulica sob condições de saturação e de forma mais pronunciada a partir das dosagens maiores que $400 \mathrm{~m}^{3} \mathrm{ha}^{-1}$. A aplicação do método do perfil instantâneo em condições de laboratório na caracterização da condutividade hidráulica do solo não saturado foi sati sfatória, havendo concordância razoável dos valores da condutividade hidráulica do solo saturado, obtidos por esse método, com os obtidos experimentalmente pela utilização do infiltrômetro de carga constante. Não houve diferença expressiva entre os valores obtidos da condutividade hidráulica do solo não saturado entre os tratamentos com água e vinhaça.
\end{abstract}

Termos de indexação: vinhaça, condutividade hidráulica, solo não saturado.

\footnotetext{
(1) Recebido para publicação em julho de 1997 e aprovado em março de 1998.

(2) Pesquisador autônomo.

(3) Departamento de Física e M eteorologia, Escola Superior deAgricultura “Luiz de Queiroz”, USP. CEP 13418-900 Piracicaba (SP). E-mail: pllibard@carpa.ciagri.usp.br. Bolsista do CNPq.

(4) Pesquisador Científico, Seção de Pedologia, InstitutoAgronômico de Campinas. Caixa Postal 28, CEP 13001-970 Campinas (SP). E-mail: otavio@sigmabbs.com.br. Bolsista do CNPq.
} 


\title{
SUMMARY: HYDRAULIC CONDUCTIVITY OF PACKED SAMPLES OF AN OXISOL TREATED WITH WATER/ VINASSE
}

\begin{abstract}
This study was carried out at the Center for Nuclear Energy in Agriculture (CENA), Piracicaba, State of São Paulo, Brazil, with the objective of obtaining information about the effect of different application levels of water/ vinasse $\left(100,200,400,600,800\right.$ and $1,000 \mathrm{~m}^{3} \mathrm{ha}^{-1}$ ) on hydraulic conductivity of soil samples homogeneously packed in columns. A constant head infiltrometer and the instantaneous water profile method were utilized to determine saturated and unsaturated soil hydraulic conductivity, respectively. Theincrease of thevinasse application level s caused a gradual decreasein the saturated hydraulic conductivity, being steeper at levels higher than $400 \mathrm{~m}^{3} \mathrm{ha}^{-1}$. Thewater profileinstantaneous method to determine the hydraulic conductivity function was very well adapted to the experimental conditions, and there was a relatively good correspondence between saturated hydraulic conductivity values detemined by constant head infiltrometer and thoseestimated by this method. There was no substantial difference in the unsaturated hydraulic conductivity values betwen water and vinasse treatments.
\end{abstract}

Index terms: vinasse, hydraulic conductivity, unsaturated soil.

\section{INTRODUÇÃO}

A alternativa de utilização da vinhaça como fertilizantejá é rotina em muitas regiões canaviei ras do País. O aumento de produção al cançada, especialmente para a cultura da cana-de-açúcar, é notório (Orlando Filho et al., 1983).

Diversos estudos desenvolvidos em nossas condições mostraram alterações nas propriedades quími cas dos sol os que receberam vinhaça (Camargo et al., 1983, 1984, 1987; Leal et al., 1983; Sengik et al., 1988). Com menor intensidade, estudos de mi crobiologia do solo (Lima, 1980; Lopes et al ., 1986) e de física de solo (Rezende, 1979; Camargo et al., 1983) foram realizados.

Entre as propriedade físicas do solo, a condutividade hidráulica merece destaque, dada sua relevância em projetos de irrigação, disposição de resíduos líquidos e conservação do solo. Assim, um estudo relativo às alterações que a aplicação de vinhaça poderia acarretar na condutividade hidráulica de um solo é importante subsídio para aumentar a compreensão da dinâmica da água em tal sistema.

Andrioli (1982), comparando os valores de profundidade da frente de molhamento (penetrabilidade) para água pura e água de vinhaça infiltradas em colunas de solo no horizonte $B$ de um Podzólico Vermelho-Amarelo, verificou que as equações de disponibilidade e de penetrabilidade podem ser utilizadas na descrição do processo de infiltração horizontal de água da vinhaça no solo. Por sua vez, Silva et al. (1976) notaram que infil trações repetidas de vinhaça em Latossolo Vermelho-A marelo promoveram acentuada diminuição nos valores de penetrabilidade.
Este trabalho teve por objetivos: a) realizar um estudo sobre o efeito da aplicação de vinhaça em diversas dosagens na condutividade hidráulica do solo saturado $\left(K_{0}\right)$ em condições de laboratório, usando um infiltrômetro de carga constante para sua determinação; b) caracterizar a função $K(\theta)$, isto é, a condutividade hidráulica em função da umidade do solo $\theta$ durante o período de redistribuição da água, aplicando o método do perfil instantâneo, sob condições de laboratório, usando água e vinhaça (1.000 $\left.\mathrm{m}^{3} \mathrm{ha}^{-1}\right)$.

\section{MATERIAL E MÉTODOS}

\section{Solo}

A amostra utilizada foi col etada no horizonte Ap de um Latossolo Roxo distrófico, Unidade Barão Geraldo (Oliveira et al., 1979) com $360 \mathrm{~g} \mathrm{~kg}^{-1}$ de argila, $\mathrm{pH}_{\mathrm{H}_{2} \mathrm{O}}=5,3$, soma de bases $14,6 \mathrm{mmol}_{\mathrm{c}(+)} \mathrm{kg}^{-1}$ $\mathrm{eV} \%=28$.

\section{Vinhaça}

A vinhaça empregada era oriunda da destilaria de álcool da Usina Santa Helena, Piracicaba (SP), e apresentava relação $\mathrm{C} / \mathrm{N}=6$, potássio $2.940 \mu \mathrm{g} \mathrm{mL}-1$, cál cio $1.300 \mu \mathrm{g} \mathrm{mL}-1$, magnésio $=250 \mu \mathrm{g} \mathrm{mL}^{-1} \mathrm{e}$ $15 \mu \mathrm{g} \mathrm{mL}^{-1}$ de sódio. A vinhaça foi aplicada, previamente, no início das determinações às col unas com as amostras de solo em doses correspondentes a 0 (testemunha), 100, 200, 400, 600, 800 e $1.000 \mathrm{~m}^{3}$ ha-1. Em experimento paralelo, o mesmo procedimento foi utilizado, aplicando-se iguais quantidades de água. 


\section{Preparação das amostras de solo e seu acondicionamento em colunas}

As amostras de solo utilizadas foram deixadas secar à sombra e passadas em peneira de malha $1 \mathrm{~mm}$. O acondicionamento foi feito em colunas de plástico acrílico de 0,60 e 1,20 m de comprimento, $57 \mathrm{~mm}$ de diâmetro interno e com espessura de parede de 3,0 $\mathrm{mm}$. As colunas de $0,60 \mathrm{~m}$ de comprimento foram utilizadas na determinação da condutividade hidráulica do solo saturado pelo método do infiltrômetro de carga constante. As colunas de 1,20 m de comprimento foram utilizadas na determinação da função $K(\theta)$, pelo método de Libardi et al. (1980). Essas colunas eram abertas numa extremidade e fechadas na outra com filtro de papel.

Para o enchimento da col una, um funil de haste longa era introduzido na col una e cheio com a terra. Depois, o funil era levantado vagarosamente, permitindo a passagem da terra para a coluna; no mesmo tempo em que era colocada mais terra no funil. Isto permitia uma separação mínima das partículas de solo. U ma vez cheia, batia-sena col una com ajuda de um martelo de borracha, até obter a densidade que o solo apresentava nas condições naturais de campo $\left(1,19 \mathrm{Mg} \mathrm{m}^{-3}\right)$. Evidentemente, neste processo, era simulada apenas a densidade do solo, não sendo possível reproduzir sua estrutura. Finalmente, retirava-se quantidade suficiente de terra para deixar um espaçolivre de 0,10 m entre a superfície da amostra de solo e a borda superior da coluna.

\section{Verificação da uniformidade de compactação das colunas de solo}

Com a finalidade de verificar a influência da uniformidade de compactação sobre os valores de condutividade hidráulica obtidos para as diversas dosagens de água e vinhaça utilizadas, realizou-se um experimento preliminar de infiltração vertical em colunas de solo, sem aplicação prévia de água ou vinhaça, com três repetições, obedecendo, rigorosamente, aos critérios de preparação e acondicionamento das amostras descritos no item anterior.

\section{Condutividade hidráulica do solo saturado $\left(K_{0}\right)$ determinada por meio de um infiltrômetro de carga constante}

Aplicou-se a dose selecionada de vinhaça (ou água) na coluna de solo, conforme os tratamentos anteriormente descritos (por exemplo, para a dosagem de $1.000 \mathrm{~m}^{3}$ ha-1, o volume de líquido aplicado, tendo em conta a área da coluna, foi de $0,255 \mathrm{~L}$ ) para, depois de 24 horas, proceder-se à infiltração vertical deágua. I niciou-se o processo de infiltração, registrando a leitura numa bureta de Mariotte (que mantinha uma carga hidráulica de 0,001 m sobre a superfície do solo) e o tempo com auxílio de um cronômetro. Periodicamente, o tempo e o vol ume de água adicionado ao sol o eram medidos até ser atingida a condição de infiltração constante.

\section{Determinação do valor $K(\theta)$ pelo método de} Libardi et al. (1980) sob condições de laboratório

I nicial mente, procedeu-seà infiltração vertical de água ou vinhaça (na dosagem de $1.000 \mathrm{~m}^{3}$ ha-1) na coluna de solo, atendendo aos mesmos critérios relativos ao procedimento experimental para determi nação da condutividade do sol o saturado $\left(\mathrm{K}_{0}\right)$ por meio do infiltrômetro de carga constante. Atingida a condição de infiltração constante, interrompeu-se o processo de infiltração, e iniciouse o de redistribuição, imediatamente, com o auxílio da técnica de radiação gama (Ferraz, 1983). Foram realizadas diversas determinações ao longo da coluna, para obtenção do perfil de umidade ( $\theta$ vs z ) em $\mathrm{t}=0$, ou seja, início do processo de redistribuição.

A condutividade hidráulica obtida durante o período de redistribuição de água foi estimada pelo método de Libardi et al. (1980), sob condições de laboratório, nos seguintes tempos: 0, 1, 2, 3, 4, 5, 6, 7, $8,9,10,11,12,13,14,15$ e 20 dias. De acordo com o método, durante o período de redistribuição, a equação que relaciona a umidade com o tempo é:

$$
\theta=\theta_{\mathrm{o}}-\frac{1}{\beta} \ln \left(1+\frac{\mathrm{K}_{\mathrm{o}} \mathrm{t}}{\mathrm{az}}\right)
$$

em que:

$\theta$ e $\theta_{0}=$ umidade do solo $\left(\mathrm{m}^{3} \mathrm{~m}^{-3}\right)$ nos tempos (s) $\mathrm{t}=\mathrm{t}$ et $=0$;

$\mathrm{t}$ = tempo de redistribuição (s);

$\mathrm{a}=$ parâmetro que relaciona $\mathrm{a}$ umidade do solo na profundidade $z$ e a umidade média do solo desde a superfície até a profundidadez;

A partir desta equação, podem-se calcular os valores de $K_{0}$ e de $\beta$ de cada profundidade com os quais se obtém diretamente a equação que relaciona a condutividade hidráulica $\mathrm{K}$ com a umidade $\theta$ :

$$
\mathrm{K}=\mathrm{K}(\theta)=\mathrm{K}_{\mathrm{o}} \mathrm{e}^{\beta\left(\theta-\theta_{0}\right)}
$$

em que:

$\mathrm{K}=$ condutividade hidráulica do solo $\left(\mathrm{m} \mathrm{s}^{-1}\right)$ na umidade $\theta\left(\mathrm{m}^{3} \mathrm{~m}^{-3}\right)$;

$\mathrm{K}_{\mathrm{o}}=$ condutividade hidráulica do sol o no tempo zero de redistribuição $(\mathrm{t}=0)$;

$\theta_{\mathrm{o}}=$ umidade do solo $\left(\mathrm{m}^{3} \mathrm{~m}^{-3}\right)$ no tempo $(\mathrm{s}) \mathrm{t}=0$;

$\beta=$ constante que traduz a rapidez com que $K$ diminui $\operatorname{com} \theta$.

\section{Umidade das colunas de solo}

A umidade ao longo da coluna de solo foi determinada pelo método da atenuação da radiação gama (Davidson et al., 1963). A fonte radioativa 
emissora de raios $\gamma$ utilizada foi o ${ }^{137} \mathrm{Cs}$ de atividade atual de $96 \mathrm{mCi}$, eosistema de detecçãofoi um conjunto da Nudear Chicago de detecção por cintilaçãosólida.

Os feixes de radiação, tanto o emergente da fonte quanto o incidente no cristal, foram devidamente colimados numa área circular de 4,45 mm². A coluna de sol o para medida da umidade era sempre colocada na horizontal e perpendicularmente ao feixe de radiação sobre um trilho de ferro que facilitava sua movimentação e fazia com que os raios gama atravessassem a parte mais espessa da coluna.

A equação utilizada no cál culo da umidade $\theta$ ao longo da col una foi :

$$
\theta=\frac{\mathrm{In} \mathrm{I} / \mathrm{I}^{\prime}}{\mu_{\mathrm{a}} \mathrm{x}}
$$

em que I = intensidade do feixe de radiação (cpm) emergente da amostra com a umidade inicial (solo seco ao ar); I' =intensi dade do feixe de radiação (cpm) emergente da amostra após o processo de infil tração de água, $\mu_{\mathrm{a}}=$ coeficiente de atenuação de massa da água $\left(\mathrm{cm}^{2} \mathrm{~g}^{-1}\right)$ ex =espessura da amostra de solo (cm).

\section{RESULTADOS E DISCUSSÃO}

\section{Uniformidade de compactação das colunas de solo}

Os resultados do teste prévio de infiltração, para verificar a influência da uniformidade de compactação na condutividade hidráulica, encontram-se na figura 1. A grande semel hança dos valores de $K_{0}$ e da lei de infiltração das três repetições (Figura 1 ) comprova que a maneira utilizada para acondicionar o solo à coluna não causaria variação nos val ores de $K_{0}$ e da função $K(\theta)$ obti dos nas diversas col unas, se se utilizasse uma só repetição. A realização desse experimento se fez necessária, para verificar se foram dadas condições deigualdadeem todos os tratamentos, no queserefere ao grau de compactação, o qual, certamente, influiria nos valores de condutividade hidráulica obtidos.

\section{Taxa de infiltração em função do tempo decorrido} e condutividade hidráulica do solo saturado $\left(K_{0}\right)$

I gualmente ao experimento preliminar, com os valores medidos do volume de água que entrou na coluna de solo por unidade de área de sua secção transversal e do tempo decorrido, calcularam-se os valores da taxa de infiltração. Para o cálculo da condutividade hidráulica do sol o saturado $\left(\mathrm{K}_{0}\right)$, para cada tratamento, foram feitos os gráficos da taxa de infiltração em função do tempo. Quando a taxa de infiltração praticamente não mais variava com o tempo, o valor obtido nesse momento, conforme a teoria clássica da infil tração (Libardi, 1995), era considerado como o valor de $\mathrm{K}_{\mathrm{o}}$. No caso presente, os valores de $K_{0}$ foram estimados pela média dos quatro últimos valores da taxa de infiltração. Com os valores de $\mathrm{K}_{\mathrm{o}}$ assim obtidos, elaborou-se o gráfico mostrado na figura 2.

Nesta figura, observa-se que, com o aumento nas dosagens água/vinhaça, os valores de $\mathrm{K}_{\mathrm{o}}$ foram diminuindo gradativamentee, deforma substancial, para os tratamentos com mais de $400 \mathrm{~m}^{3}$ ha-1, sofrendo um decréscimo de até $77 \%$, se comparados aos do tratamento sem água e vinhaça $\left(0 \mathrm{~m}^{3}\right.$ ha-1, Figura 1) com aquele com $1.000 \mathrm{~m}^{3}$ ha-1 de vinhaça.

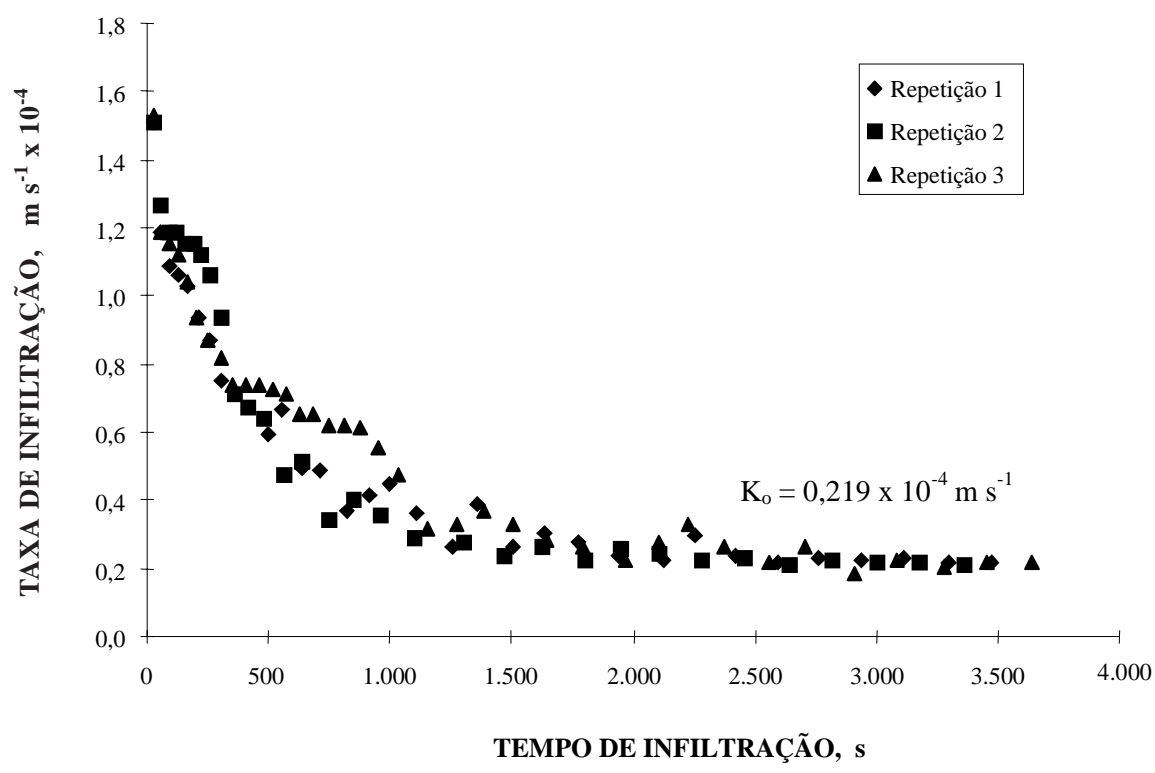

Figura 1. Teste de infiltração para as três repetições do experimento preliminar. 
Em termos médios, os valores de $K_{0}$ para as dosagens 100,200 e $400 \mathrm{~m}^{3}$ ha-1 $^{-1}$ foram $22 \%$ inferiores nos tratamentos com vinhaça do que nos tratamentos com água. Nas dosagens 600, 800 e $1.000 \mathrm{~m}^{3}$ ha-1, a diminuição foi, em média, de 52\%. Portanto, em dosagens menores (até $400 \mathrm{~m}^{3}$ ha-1), os valores de $\mathrm{K}_{0}$, embora também tenham apresentado diminuição, esta não passou de $25 \%$, o que constitui decréscimo muito pequeno e, provavel mente, pouco importante, uma vez quea mai oria das usinas nunca usa dosagens superiores a $150 \mathrm{~m}^{3} \mathrm{ha}^{-1}$ em soqueiras de cana-de-açúcar. Um detalhe a ser ressaltado refere-se à variação dos valores de $K_{0}$ para as diferentes dosagens de água. Teoricamente, era esperado que os valores de $K_{0}$ para essas dosagens se mantivessem constantes, o que realmente não ocorreu. As quedas de $K_{0}$ para os tratamentos com água ocorreram paralel amente aos tratamentos com vinhaça, porém com menor magnitude. Possivel mente, isto decorreu do mol hamento prévio de amostras de sol o por ocasião da aplicação das dosagens, conforme os tratamentos estabelecidos, oqual deveter causado alteração na distribuição das partículas de solo. 0 decréscimo constatado com maior amplitude para vinhaça pode estar ligado ao fato de haver uma acumulação dos sólidos em suspensão no líquido ao longo do perfil, formando uma camada de alta impedância hidráulica, o que já foi constatado por Bouwer \& Chaney (1974) e Rawitz \& Burns (1981).

\section{Caracterização do parâmetro $K(\theta)$ em coluna de solo com infiltração de água e com infiltração de vinhaça}

Com os valores da umidade volumétrica para os diversos tempos e profundidades, durante o período de redistribuição da água, para as colunas de solo infiltradas com água e com vinhaça na dosagem de $1.000 \mathrm{~m}^{3}$ ha-1, obtiveram-se, por meio do método de Libardi et al. (1980), as seguintes equações para a condutividade hidráulica:

usando água:

$$
\mathrm{K}(\theta)=8,036 \times 10^{-6} \exp 52,910(\theta-0,424) \rightarrow \mathrm{m} \mathrm{s}^{-1} \text { (4) }
$$

e usando vinhaça:

$$
\mathrm{K}(\theta)=3,716 \times 10^{-6} \exp 54,645(\theta-0,413) \rightarrow \mathrm{m} \mathrm{s}^{-1}(5)
$$

Os dados de umidade, que deram origem às equações (4) e (5) e parte do gráfico da figura 3, encontram-se nos quadros 1 e 2 , respectivamente. No tempo zero de redistribuição, a frente de molhamento encontrava-se a, aproximadamente, $0,35 \mathrm{~m}$ de profundidade (Figura 3). Dada a grande homogeneidade das col unas de solo e, tendo em vista o interesse de comparação dos dois tratamentos (água e vinhaça), trabal hou-se com os dados médios de $\theta$ dos quadros 1 e 2 para obtenção das equações para $K(\theta)$. Na obtenção dessas equações por este método, os dados precisavam ser ajustados à equação (1). Para ambos os tratamentos, a regressão de $\theta$ versus In t (Libardi et al. 1980) mostrou coeficiente de determinação ( $\left.R^{2}\right)$ maior do que 0,94 , condição necessária para a aplicação do método. Com esses resultados, pode-se concluir que o método referido para caracterização da função $K(\theta)$ se aplica para condições de laboratório, nas condições estudadas.

Pelas equações (4) e (5), que nada mais são que a equação (2) para o sol o em questão, pode-se verificar que, para a água, $\mathrm{K}_{0}=0,80310^{-5} \mathrm{~m} \mathrm{~s}^{-1} \mathrm{e}$, para a vinhaça, $\mathrm{K}_{\mathrm{o}}=0,372 \times 10^{-5} \mathrm{~m} \mathrm{~s}^{-1}$. Os valores obtidos pelo infiltrômetro (Figura 2) nesta dosagem (1.000 $\mathrm{m}^{3}$ ha-1) foram, respectivamente, $1,083 \times 10^{-5} \mathrm{~m} \mathrm{~s}^{-1} \mathrm{e}$ $0,517 \times 10^{-5} \mathrm{~m} \mathrm{~s}^{-1}$, oquemostra que, emambos os casos

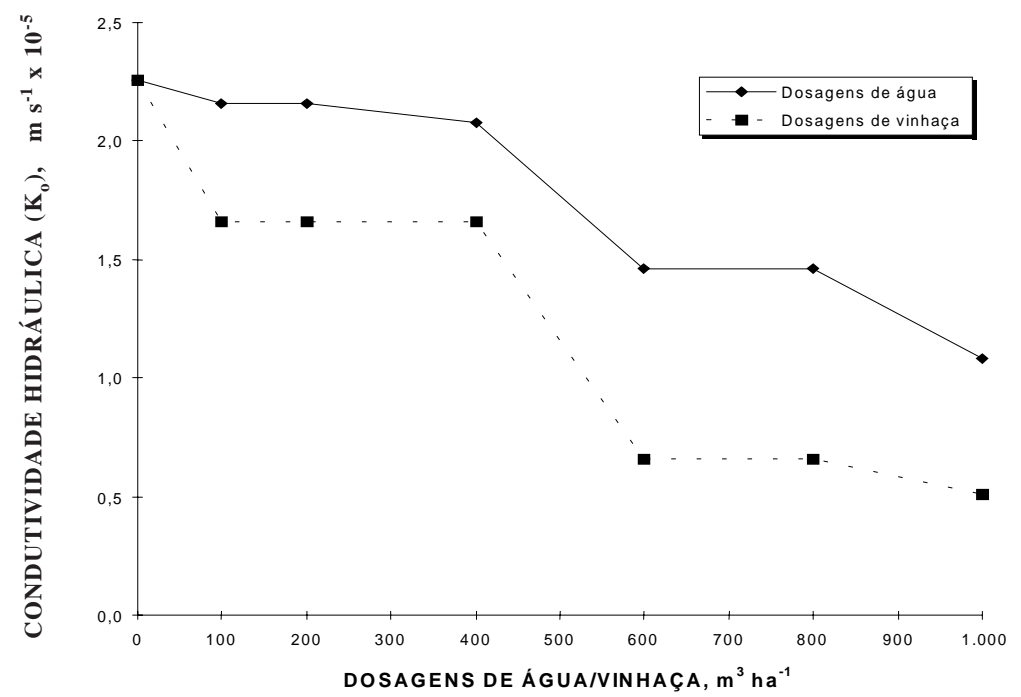

Figura 2. Condutividade hidráulica do solo saturado, $K_{o}$, obtida pelos gráficos da taxa de infiltração versus tempo decorrido, em função das dosagens de água/vinhaça aplicadas em colunas de solo homogêneo. 
(água e vinhaça), o valor de $\mathrm{K}_{0}$, obtido pelo método do infiltrômetro, foi mai or do queo val or de $\mathrm{K}_{0}$, obtido pel o método de Libardi et al. (1980). No caso da água, o desvio foi de $34,8 \%$ e, no caso da vinhaça, de $39 \%$.

Nos quadros 1 e2, observa-se que, no tratamento com água, a umidade de saturação foi superior $\left(0,424 \mathrm{~m}^{3} \mathrm{~m}^{-3}\right)$ à do tratamento com vinhaça $\left(0,413 \mathrm{~m}^{3} \mathrm{~m}-3\right)$. Tal fato pode explicar os valores maiores de $K_{0}$ no tratamento com água em relação ao tratamento com vinhaça do método da infiltração (Figura 2). Utilizando essas duas equações e, com base na faixa de valores de umidade da figura 2 , elaborou-se o quadro 3 para se ter uma idéia da variação da condutividade hidrául ica com a umi dade.

Quadro 1. Umidade volumétrica $(\theta)$ para os diversos tempos $(t)$ e profundidades $(z)$, durante o período de redistribuiç̧ão da água, para coluna de solo tratada com água, na dosagem de $1.000 \mathrm{~m}^{3} \mathrm{ha}^{-1}$

\begin{tabular}{|c|c|c|c|c|c|c|c|c|}
\hline \multirow{2}{*}{ Tempo } & \multicolumn{7}{|c|}{ Umidade volumétrica $\theta\left(\mathrm{m}^{3} \mathrm{~m}^{-3}\right)$} & \multirow{2}{*}{$\begin{array}{c}\bar{\theta} \\
\text { Média }\end{array}$} \\
\hline & $z=0,02$ & $z=0,05$ & $z=0,10$ & $z=0,15$ & $z=0,20$ & $z=0,25$ & $z=0,30$ & \\
\hline \multicolumn{9}{|l|}{ Hora } \\
\hline 0 & 0,4450 & 0,4360 & 0,4320 & 0,4180 & 0,4250 & 0,4160 & 0,3970 & 0,4241 \\
\hline 24 & 0,3420 & 0,3370 & 0,3260 & 0,3240 & 0,3160 & 0,3120 & 0,3100 & 0,3239 \\
\hline 48 & 0,3380 & 0,3340 & 0,3200 & 0,3220 & 0,3120 & 0,3080 & 0,3090 & 0,3204 \\
\hline 72 & 0,3340 & 0,3300 & 0,3160 & 0,3190 & 0,3060 & 0,3070 & 0,3050 & 0,3167 \\
\hline 96 & 0,3270 & 0,3250 & 0,3090 & 0,3160 & 0,3000 & 0,3020 & 0,3010 & 0,3114 \\
\hline 120 & 0,3220 & 0,3200 & 0,3060 & 0,3140 & 0,2940 & 0,2960 & 0,2950 & 0,3067 \\
\hline 144 & 0,3180 & 0,3160 & 0,3030 & 0,3100 & 0,2900 & 0,2910 & 0,2920 & 0,3029 \\
\hline 168 & 0,3140 & 0,3120 & 0,2980 & 0,3070 & 0,2860 & 0,2870 & 0,2900 & 0,2991 \\
\hline 192 & 0,3100 & 0,3070 & 0,2960 & 0,2980 & 0,2820 & 0,2830 & 0,2860 & 0,2946 \\
\hline 240 & 0,3080 & 0,3040 & 0,2920 & 0,2940 & 0,2770 & 0,2780 & 0,2840 & 0,2910 \\
\hline 264 & 0,3040 & 0,3030 & 0,2850 & 0,2920 & 0,2740 & 0,2750 & 0,2800 & 0,2876 \\
\hline 312 & 0,3000 & 0,2990 & 0,2800 & 0,2860 & 0,2700 & 0,2720 & 0,2770 & 0,2834 \\
\hline 336 & 0,2960 & 0,2950 & 0,2770 & 0,2840 & 0,2660 & 0,2680 & 0,2740 & 0,2800 \\
\hline 360 & 0,2920 & 0,2930 & 0,2730 & 0,2820 & 0,2620 & 0,2640 & 0,2720 & 0,2769 \\
\hline 480 & 0,2860 & 0,2900 & 0,2700 & 0,2800 & 0,2560 & 0,2600 & 0,2710 & 0,2733 \\
\hline
\end{tabular}

Quadro 2. Umidade volumétrica $(\theta)$ para os diversos tempos $(t)$ e profundidades $(z)$, durante o período de redistribuição da vinhaça, para coluna de solo tratada com vinhaça, na dosagem de $1.000 \mathrm{~m}^{3} \mathrm{ha}^{-1}$

\begin{tabular}{|c|c|c|c|c|c|c|c|c|}
\hline \multirow{2}{*}{ Tempo } & \multicolumn{7}{|c|}{ Umidade volumétrica $\theta\left(\mathrm{m}^{3} \mathbf{m}^{-3}\right)$} & \multirow{2}{*}{$\begin{array}{c}\bar{\theta} \\
\text { Média }\end{array}$} \\
\hline & $z=0,02$ & $z=0,05$ & $z=0,10$ & $z=0,15$ & $z=0,20$ & $z=0,25$ & $z=0,30$ & \\
\hline \multicolumn{9}{|l|}{ Hora } \\
\hline 0 & 0,4360 & 0,4200 & 0,4120 & 0,4000 & 0,4150 & 0,4090 & 0,3960 & 0,4126 \\
\hline 24 & 0,3480 & 0,3440 & 0,3280 & 0,3340 & 0,3220 & 0,3240 & 0,3250 & 0,3321 \\
\hline 48 & 0,3370 & 0,3360 & 0,3200 & 0,3320 & 0,3140 & 0,3160 & 0,3200 & 0,3250 \\
\hline 72 & 0,3330 & 0,3300 & 0,3180 & 0,3290 & 0,3100 & 0,3120 & 0,3180 & 0,3214 \\
\hline 96 & 0,3280 & 0,3240 & 0,3100 & 0,3260 & 0,3060 & 0,3050 & 0,3160 & 0,3164 \\
\hline 120 & 0,3240 & 0,3200 & 0,3080 & 0,3240 & 0,2970 & 0,2980 & 0,3110 & 0,3094 \\
\hline 144 & 0,3200 & 0,3170 & 0,3040 & 0,3200 & 0,2950 & 0,2930 & 0,3100 & 0,3084 \\
\hline 168 & 0,3160 & 0,3130 & 0,3000 & 0,3150 & 0,2920 & 0,2880 & 0,3090 & 0,3047 \\
\hline 192 & 0,3130 & 0,3100 & 0,2910 & 0,3130 & 0,2900 & 0,2860 & 0,3070 & 0,3014 \\
\hline 240 & 0,3100 & 0,3080 & 0,2900 & 0,3100 & 0,2890 & 0,2750 & 0,2990 & 0,2973 \\
\hline 264 & 0,3070 & 0,3060 & 0,2860 & 0,3080 & 0,2870 & 0,2720 & 0,2950 & 0,2944 \\
\hline 312 & 0,3040 & 0,3030 & 0,2820 & 0,3060 & 0,2780 & 0,2700 & 0,2930 & 0,2909 \\
\hline 336 & 0,2990 & 0,3010 & 0,2790 & 0,3040 & 0,2740 & 0,2680 & 0,2920 & 0,2880 \\
\hline 360 & 0,2940 & 0,2980 & 0,2740 & 0,3030 & 0,2690 & 0,2640 & 0,2880 & 0,2843 \\
\hline 480 & 0,2930 & 0,2960 & 0,2700 & 0,3000 & 0,2600 & 0,2620 & 0,2840 & 0,2807 \\
\hline
\end{tabular}




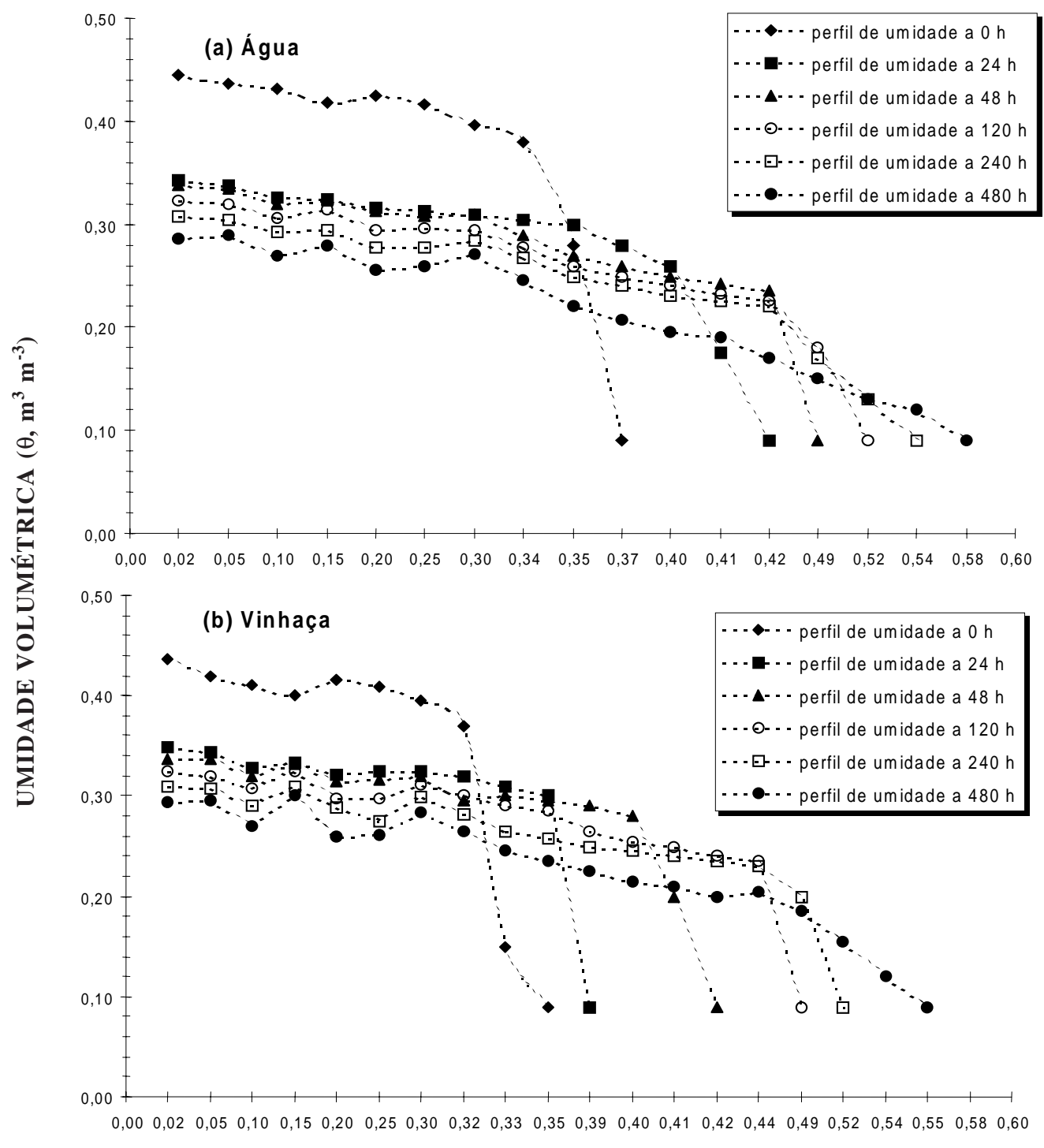

PROFUNDIDADE $(z, m)$

Figura 3. Perfis de umidade durante o processo de redistribuição em coluna de solo tratado com água (a) ou vinhaça (b), na dosagem de $1.000 \mathrm{~m}^{3} \mathrm{ha}^{-1}$.

Quadro 3. Relação entre condutividade hidráulica e umidade do solo

\begin{tabular}{ccc}
\hline \multirow{2}{*}{ Umidade } & \multicolumn{2}{c}{ Condutividade hidráulica $\left(\mathbf{m ~ s}^{\mathbf{1}}\right)$} \\
\cline { 2 - 3 } & \multicolumn{1}{c}{ Água } & Vinhaça \\
\hline $\mathrm{m}^{3} \mathrm{~m}^{-3}$ & & \\
0,424 & $8,03610^{-6}$ & - \\
0,413 & $4,49010^{-6}$ & $3,71610^{-6}$ \\
0,380 & $7,83410^{-7}$ & $6,12210^{-7}$ \\
0,340 & $9,43710^{-8}$ & $6,88110^{-8}$ \\
0,300 & $1,13710^{-8}$ & $7,73310^{-9}$ \\
0,250 & $8,06810^{-10}$ & $5,03210^{-10}$ \\
0,200 & $5,73010^{-11}$ & $3,27010^{-11}$ \\
\hline
\end{tabular}

Observa-se que, para valores de umidade inferiores a 0,30 $\mathrm{m}^{3} \mathrm{~m}^{-3}$, a condutividade hidráulica é praticamente nula e que, para a faixa úmida (superior a 0,30 $\mathrm{m}^{3} \mathrm{~m}^{-3}$ ), a diferença entre os val ores de condutividade hidráulica obtidos entre os tratamentos com água e vinhaça não foi expressiva, apesar desenotar uma tendência de val ores maiores para o tratamento com água (Quadro 3).

\section{CONCLUSÕES}

1. Na condição de saturação, a condutividade hidráulica diminui com o aumento das dosagens de vinhaça, notadamente para os tratamentos com mais de $400 \mathrm{~m}^{3} \mathrm{ha}^{-1}$. 
2. Na condição de não-saturação, a condutividade hidráulica aparentemente não sofreu qualquer interferência expressiva, quando se utilizou vinhaça na dosagem de $1.000 \mathrm{~m}^{3}$ ha-1 para sua determinação, apesar dese notar certa tendência de valores maiores na determinação com água.

\section{LITE RATURA CITADA}

ANDRIOLI, I. Movimento da vinhaça no solo podzolizado Lins e Marília var. Marília. J aboticabal, Universidade Estadual de São Paulo, 1982. 89p. (Tese de Mestrado)

BOUWER, H. \& CHANEY, R.L. Land treatment of waste water. Adv. Agron., 26:133-176, 1974.

CAMARGO, O.A.; BERTON, R.S.; GERALDI, R.N. \& VALADARES, J.M.A.S. Alterações de características químicas em um latossolo roxo distrófico incubado com resíduo da indústria álcool açucareira. Bragantia, 43:125139, 1984.

CAMARGO, O.A.; VALADARES, J.M.A.S. \& GERALDI, R.N. Características químicas e físicas de solo que recebeu vinhaça por longo tempo. Campinas, I nstituto Agronômico, 1983. 30p. (Bol etim Técnico, 76)

CAMARGO, O.A.; VALADARES, J.M.A.S.; BERTON, R.S. \& TEÓFILO SOBRINHO, J. Aplicação de vinhaça no solo e efeito no teor de nitrogênio, fósforo e enxofre inorgânicos e no de alguns metais pesados. Campinas, Instituto Agronômico, 1987. 15p. (Boletim Técnico, 8)

DAVIDSON, J.M.; BIGGAR, J.M. \& NIELSEN, D.R. Gamma radiation attenuation for measuring bulk density and transient water flow in porous materials. J. Geoph. Res., 68:4777-4783, 1963

FERRAZ, E.S.B. Gamma ray atenuation to measure water content and/or bulk densities of porous media. IAEA-SM267/41. SY MPOSIUM , AIX-EN-PROVE N CE, France, 1983. Proceedings. (s.l., s.ed.), 1983. p.449-460.
LEAL, J .R.; AMARAL SOBRINHO, N.M.B.;VELLOSO, A.C.X. \& ROSSIELO, R.O.P. Potencial redox e pH: variações em um sol o tratado com vinhaça. R. Bras. Ci. Sol o, 7:257-261, 1983.

LIBARDI, P.L.; REICHARDT, K.; NIELSEN, D.R. \& BIGGAR, J.W. Simple field methods for estimating soil hydraulic conductivity. Soil Sci. Soc. Am. J., 44:3-7, 1980.

LIBARDI, P.L. "Dinâmica da água no solo”. Piracicaba, DFM/ ESALQ/USP, 1995. 497p.

LIMA, I.J . Efeitos de aplicação de vinhaça sobre a microflora do solo. Rio de J aneiro, Universidade Federal Rural do Rio de J aneiro, 1980. 150p. (Tese de Mestrado)

LOPES, E.S.; PERON, S.C.; PORTUGAL, E.P.; CAMARGO, O.A. \& FREITAS, S.S. Atividades respiratória de solo tratado com vinhaça e herbicida. Bragantia, 45:205-210, 1986.

OLIVEIRA, J.B.; MENK, J.R.F. \& ROTTA, C.L. Levantamento pedológico semi-detal hado dos sol os do Estado de São Paulo - Quadrícula de Campinas. Rio deJ aneiro, IBGE, 1979. 172p.

ORLANDO FILHO,J .; SILVA, G.M.A. \& LEME, E.J .A. Utilização agrícola dos resíduos da agroindústria canavieira. In: ORLANDO FILHO, J ., coord. Nutrição e adubação da canade-açúcar no Brasil. Piracicaba, IAA/PLANALSUCAR, 1983. p.227-264.

RAWITZ, E. \& BURNS, S. The effects of sodium and organic matter in sewage effluent on water retention properties of soils. Soil Sci. Soc. Am. J ., 45:487-493, 1981.

REZENDE, J.O. Conseqüências da aplicação de vinhaça sobre algumas propriedades físicas de um solo aluvial (estudo de um caso). Piracicaba, Escola Superior de Agricultura Luiz de Queiroz, 1979. 112p. (Tese de Doutorado)

SENGIK, E.; RIBEIRO, A.C. \& CONDE, A.R. Efeito da vinhaça em algumas propriedades de amostras de solos de Viçosa (MG). R. Bras. Ci. Solo, 12:11-15, 1988.

SILVA, G.M.A.; CASTRO, L.U.P. \& MAGRO,J .A. Comportamento agroindustrial da cana-de-açúcar em solo irrigado e não irrigado com vinhaça. In: SEMINÁRIO COOPERSUCAR DA AGROINDÚSTRIA AÇÚCAREIRA, 4., Águas de Lindóia, 1976. Anais. Águas de Lindóia, COPERSUCAR, 1976. p.107-122. 